\title{
Mosaic variegated aneuploidy syndrome
}

INSERM

\section{Source}

INSERM. (1999). Orphanet: an online rare disease and orphan drug data base. Mosaic variegated aneuploidy syndrome. ORPHA:1052

Mosaic varieg ated aneuploidy (MVA) syndrome is a chromosomal anomaly characterized by multiple mosaic aneuploidies that leads to a variety of phenotypic abnormalities and cancer predisposition. 